\title{
Candida Glabrata Fungemia After Amputation of an Infected Diabetic Foot
}

\author{
Takeshi Fujiwara, ${ }^{1} \quad$ Takashi Nagai, ${ }^{1} \quad$ Katsumi Kaneko, ${ }^{1}$ \\ Kazunori Tonouchi, ${ }^{1}$ Kazuma Okamoto, ${ }^{1}$ Ken Masubuchi, ${ }^{1}$ \\ Takao Ishizuka, ${ }^{1}$ Kunihiko Iizuka ${ }^{1}$ and Yoshio Umegae $^{1}$
}

\begin{abstract}
A 58-year-old woman suffered from left pyelonephritis with diabetic triopathy on admission at which time a double $\mathbf{J}$ stent was inserted in the left ureter and was left untreated for a year. She was admitted due to fever, thirst, polydipsia, polyuria and, left 1,2-toe ulcer and vacuole. We diagnosed diabetic foot infections. We used $6 \mathrm{~g}$ of ampicillin-sulbactum and $40 \mu \mathrm{g}$ of alprostadil alfadex daily in addition to diet and insulin therapy for diabetes mellitus. As the toe lesion deteriorated, a left foot amputation was performed at the $11^{\text {th }}$ day. The subfever continued and the consciousness level deteriorated from alert to 100 on the Japan coma scale and acute respiratory failure occurred 21 days after operation. Whole body computed tomography showed invasive lesions in bilateral pulmonary lower lobes and renal pelvic dilatation and perirenal abscess in left kidney indicating renal abscess. Milk-like urine was excreted. Urine and blood culture detected Candida glabrata. Fundoscopic exam showed retinal exudates indicating mycotic endophthalmitis. We diagnosed candida glabrata sepsis from pyelonephritis. After using $200 \mathrm{mg}$ of micafungin daily, the patient recovered. In addition to exchanging the stent, treatment of diabetes mellitus is important for the prevention of severe infection. (Kitakanto Med J 2010;60: 259 263)
\end{abstract}

Key Words : diabetic gangrene, renal abscess, candida glabrata

\section{Introduction}

The incidence of infection is higher than normal in diabetic patients and infectious complications resulting in death are more frequent. ${ }^{1,2}$ Impaired leukocyte functions such as chemotaxis and bactericidal activity in diabetic patients have been shown. ${ }^{3}$ Impaired monocyte chemotaxis has also been reported. ${ }^{4}$ Abnormalities in the microvascular circulation of diabetic patients generally result in decreased tissue perfusion. ${ }^{5}$ These abnormalities may increase the risk of infection and make treatment more difficult. Foot infections are common in diabetic patients and are associated with high morbidity and risk of lower extremity amputation. ${ }^{6}$ Diabetes mellitus is present in $39 \%$ of patients with fungal urinary tract infection. ${ }^{7}$ Urinary tract abnormalities occur in $37.7 \%$ and malignancy in $22.2 \%$. Candida albicans is found in $51.8 \%$ of patients and Candida glabrata in $15.6 \% .^{7}$ Candida glabrata is the second most common isolate of candidemia and the emergence of non-albicans species of Candida is the major cause of candidemia among diabetic patients. ${ }^{8}$ Here, we report a case of candida glabrata fungemia after amputation of an infected diabetic foot.

\section{Case report}

A 58-year-old woman was admitted due to fever, thirst, polydipsia, polyuria, and left 1,2-toe injury and vacuole. She had suffered from left 1,2-toe injury for the previous 14 days and from fever, thirst, polydipsia and polyuria for the previous 3 days. Her weight was $52 \mathrm{~kg}$ at age 20. Her maximal weight was $87 \mathrm{~kg}$ at age 24. She was normally delivered at age 25 . Diabetes mellitus was indicated at age 30, but thereafter she had not been treated. She suffered from left pyelone-

1 Department of Internal Medicine, Public Tomioka General Hospital, 2073-1 Tomioka, Tomioka, Gunma 370-2393, Japan

Received: April 5, 2010

Address: TAKASHI NAGAI Department of Internal Medicine, Public Tomioka General Hospital, 2073-1 Tomioka, Tomioka, Gunma 370-2393, Japan 
phritis with diabetic triopathy at age 57. At that time a double $\mathbf{J}$ stent was inserted in the left ureter because the retrograde pyelography indicated intraureter polyp lesion. She then remained untreated for a year. Other diseases had not been indicated. She smoked 10/day and drank about $20 \mathrm{~g}$ of alcohol daily. Her father and mother also had diabetes mellitus. Her physical examination showed the following: height $158.9 \mathrm{~cm}$, weight $47 \mathrm{~kg}$ (body mass index : $18.6 \mathrm{~kg} / \mathrm{m}^{2}$ ), blood pressure $135 / 83 \mathrm{mmHg}$, pulse rate $93 / \mathrm{min}$, respiratory rate $24 / \mathrm{min}$, temperature $38.4^{\circ} \mathrm{C}$, consciousness alert. Fundoscopic examination showed background diabetic retinopathy. There were no abnormalities in the pharynx, chest or abdomen. There was no skin eruption. Diminished deep tendon reflexes and bilateral foot paresthesia indicated diabetic neuropathy. Left 1,2-toe ulcerative lesion with necrosis was detected. Laboratory data were as follows: chest X-ray film showed normal. Chest x-ray film showed normal

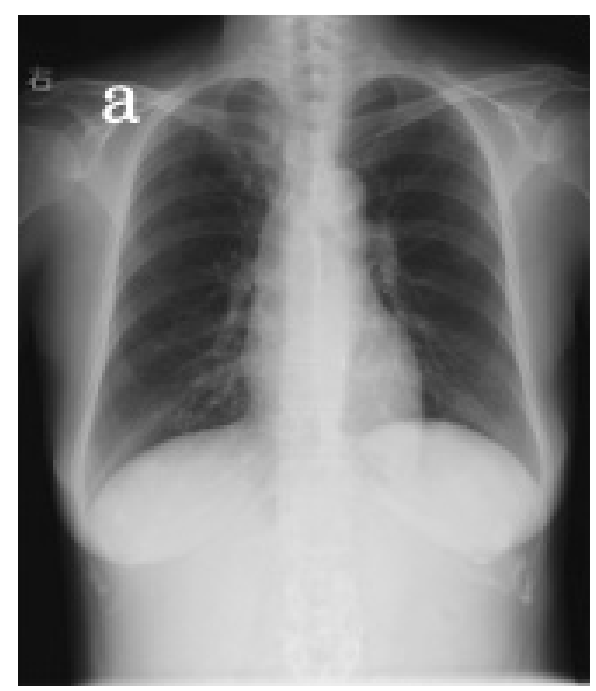

Fig. 1a Chest $x$ ray film shows normal pulmonary field at the admission.

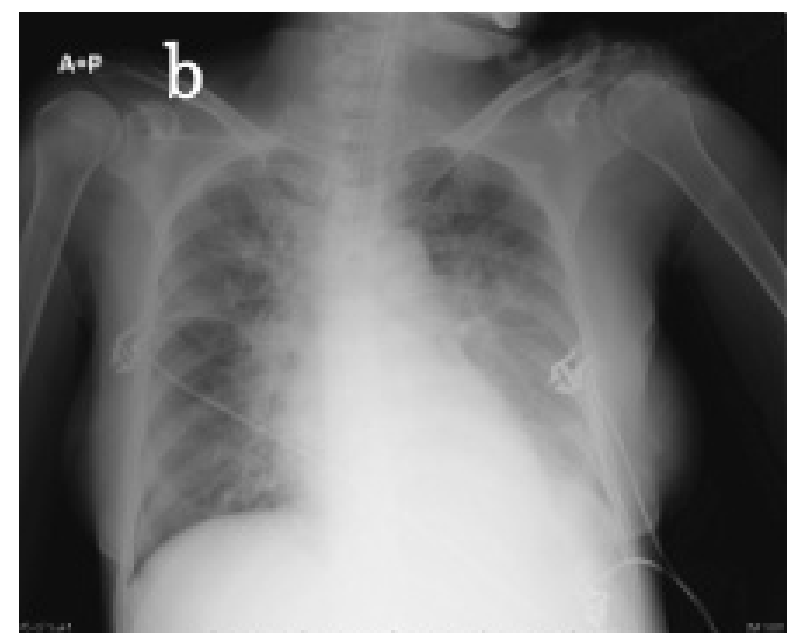

Fig. 1b Chest $x$ ray film shows cardiomegaly and bilateral homogenous lesions in the bilateral middle to lower pulmonary field in the prone position. pulmonary field (Fig. 1a). Electrocardiogram was within the normal range. Abdominal echogram showed a bright liver. Urinalysis showed proteinuria $(100 \mathrm{mg} / \mathrm{dl})$, glycosuria $(+)$ and blood + with sediment (red blood cell count 10/hpf, white blood cell count $30 / \mathrm{hpf}$ ). The white blood cell count was $24700 / \mu 1$ (basophil 0\%, eosinophil 0\%, segmented leukocyte $65 \%$, lymphocyte $25 \%$, monocyte $10 \%$ ). Albumin was $2.6 \mathrm{~g} / \mathrm{dl}, \mathrm{BUN} ; 29.8 \mathrm{mg} / \mathrm{dl}$, creatinine; $2.0 \mathrm{mg} / \mathrm{dl}$ and C-reactive protein (CRP) $; 27.4 \mathrm{mg} / \mathrm{dl}$. Fasting blood glucose was $257 \mathrm{mg} / \mathrm{dl}$ and $\mathrm{HbAlc}$; $12.2 \%$. The urinary C-peptide was $31 \mu \mathrm{g} /$ day. Creatinine clearance was $25.1 \mathrm{ml} / \mathrm{min}$. The urinary albumin excretion rate of $761 \mathrm{mg} / \mathrm{gCr}$ indicated diabetic nephropathy. Toe wound culture revealed Staphylococcus aureus and blood culture was negative (Table 1). We diagnosed diabetic foot infections followed by Staphylococcus aureus due to untreated diabetes mellitus. We used $6 \mathrm{~g}$ of ampicillinsulbactum daily and $40 \mu \mathrm{g}$ of alprostadil alfadex daily in addition to diet and insulin therapy (Humalog mix 50) for diabetes mellitus. Although the Staphylococcus aureus was sensitive to ampicillin-sulbactum, the toe lesion did not recover and the fever continued. The left foot amputation was performed at the $11^{\text {th }}$ day. After that the subfever continued and slight exudates were excreted from the operative lesion. We changed

Table 1 laboratory data on the 1st day

\begin{tabular}{|c|c|c|c|}
\hline Urinalysis & & ZTT & $8.1 \mathrm{u}$ \\
\hline protein & $100 \mathrm{mg} / \mathrm{dl}$ & TTT & $4.2 \mathrm{U}$ \\
\hline glucose & $1.0 \mathrm{~g} / \mathrm{dl}$ & BUN & $29.8 \mathrm{mg} / \mathrm{dl}$ \\
\hline blood & + & $\mathrm{Cr}$ & $2.0 \mathrm{mg} / \mathrm{dl}$ \\
\hline acetone & $(-)$ & UA & $5.2 \mathrm{mg} / \mathrm{dl}$ \\
\hline $\mathrm{RBC}$ & $10 / \mathrm{hpf}$ & $\mathrm{Na}$ & $134 \mathrm{mEq} / 1$ \\
\hline WBC & $30 / \mathrm{hpf}$ & $\mathrm{K}$ & $4.2 \mathrm{mEq} / 1$ \\
\hline & & $\mathrm{Cl}$ & $97 \mathrm{mEq} / 1$ \\
\hline Hematology & & $\mathrm{Ca}$ & $8.4 \mathrm{mg} / \mathrm{dl}$ \\
\hline $\mathrm{RBC}$ & $380 \times 10^{4} / \mu 1$ & amylase & $35 \mathrm{su} / \mathrm{dl}$ \\
\hline $\mathrm{Hb}$ & $11.1 \mathrm{~g} / \mathrm{dl}$ & $\mathrm{T}-\mathrm{CH}$ & $146 \mathrm{mg} / \mathrm{dl}$ \\
\hline $\mathrm{Ht}$ & $32.6 \%$ & $\mathrm{HDL}-\mathrm{CH}$ & $40 \mathrm{mg} / \mathrm{dl}$ \\
\hline platelet & $38.7 \times 10^{4} / \mu 1$ & TRG & $119 \mathrm{mg} / \mathrm{dl}$ \\
\hline WBC & $24700 / \mu 1$ & CRP & $27.4 \mathrm{mg} / \mathrm{dl}$ \\
\hline Baso & $0 \%$ & FBG & $257 \mathrm{mg} / \mathrm{dl}$ \\
\hline Eosino & $0 \%$ & $\mathrm{HbAlc}$ & $12.2 \%$ \\
\hline Seg & $65 \%$ & urine CPR & $31 \mu \mathrm{g} / \mathrm{day}$ \\
\hline Lymph & $25 \%$ & $\mathrm{Ccr}$ & $25.1 \mathrm{ml} / \mathrm{min}$ \\
\hline Mono & $10 \%$ & Urine protein & $761 \mathrm{mg} / \mathrm{gCr}$ \\
\hline Chemistry & & Serology & \\
\hline AST & $24 \mathrm{mU} / \mathrm{ml}$ & STS & $(-)$ \\
\hline ALT & $16 \mathrm{mU} / \mathrm{ml}$ & HBsAg & $(-)$ \\
\hline $\mathrm{LDH}$ & $223 \mathrm{mU} / \mathrm{ml}$ & anti-HCV Ab & $(-)$ \\
\hline ALP & $221 \mathrm{mU} / \mathrm{ml}$ & \multirow{2}{*}{\multicolumn{2}{|c|}{$\begin{array}{l}\text { Abscess culture } \\
\text { St. aureus }\end{array}$}} \\
\hline $\begin{array}{l}\gamma^{-\mathrm{GTP}} \\
\text { total protein }\end{array}$ & $\begin{array}{r}11 \mathrm{mU} / \mathrm{ml} \\
7.6 \mathrm{~g} / \mathrm{dl}\end{array}$ & & \\
\hline albumin & $2.6 \mathrm{~g} / \mathrm{dl}$ & \multirow{2}{*}{\multicolumn{2}{|c|}{$\begin{array}{l}\text { Blood culture } \\
\text { negative }\end{array}$}} \\
\hline T-Bil & $0.7 \mathrm{mg} / \mathrm{dl}$ & & \\
\hline
\end{tabular}




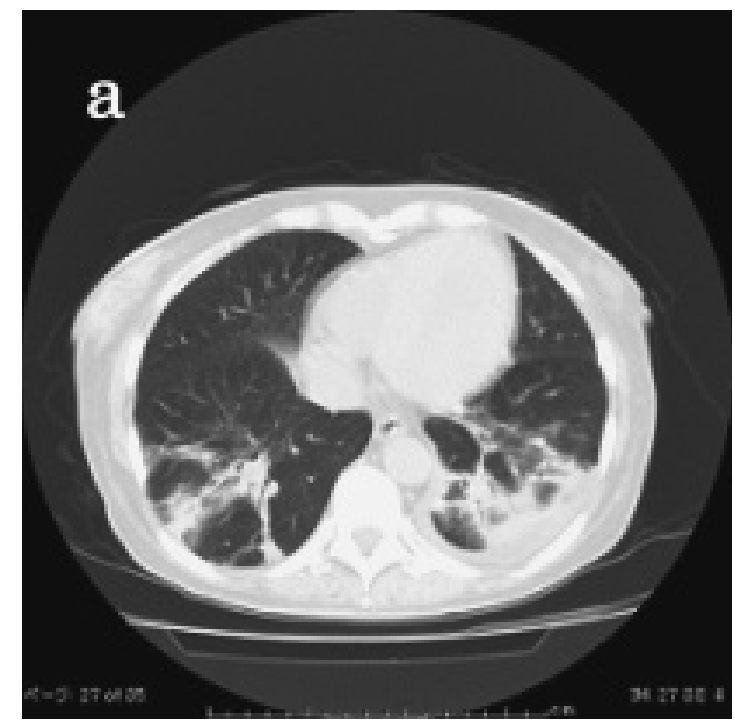

Fig. 2a Chest computed tomography shows invasive lesions in bilateral pulmonary lower lobes.

from ampicillin-sulbactum to $2 \mathrm{~g}$ of cefozopran hypdrochloride daily for covering gram-negative pathogen. The CRP decreased ranging from $11.3-12.5 \mathrm{mg} /$ dl to $5.1-6.2 \mathrm{mg} / \mathrm{dl}$. However, the subfever continued. The consciousness level deteriorated from alert to 100 on the Japan coma scale and acute respiratory failure occurred 21 days after operation $\left(\mathrm{pH} 7.407, \mathrm{pCO}_{2} 29.5\right.$ Torr, $\mathrm{pO}_{2}$ 43.9 Torr and $\mathrm{HCO}_{3} 18.2 \mathrm{mEq} / 1$ after the inhalation of $61 / \mathrm{min}$ oxygen). Chest $\mathrm{x}$-ray film showed cardiomegaly and bilateral homogenous lesions in the bilateral middle to lower pulmonary field in the prone position (Fig. 1b). Whole body computed tomography showed invasive lesions in bilateral pulmonary lower lobes (Fig. 2a) and renal pelvic dilatation and perirenal abscess in the left kidney indicating renal abscess (Fig. 2b). The electrocardiogram subsequently showed sinus tachycardia while axis deviation or STT change was not shown. The ultra cardiogram did not show abnormal valve and wall motion, or right ventricular dilatation. The white blood cell (WBC) count was $26900 / \mu 1$ (basophil $1 \%$, eosinophil $2 \%$, stab leukocyte $2 \%$, segmented leukocyte $90 \%$, lymphocyte $4 \%$, monocyte $1 \%$ ); hemoglobin ; $10.1 \mathrm{~g} / \mathrm{dl}$ and platelet count ; $47.6 \times 10^{4} /$ $\mu 1$. Renal function showed BUN;26.2 mg/dl and creatinine; $1.9 \mathrm{mg} / \mathrm{dl}$. Fasting blood glucose was 138 $\mathrm{mg} / \mathrm{dl}$ and HbAlc $8.9 \%$. The CRP was $14.7 \mathrm{mg} / \mathrm{dl}$. Urine pneumococcal Ag and legionella Ag were negative. Milk-like urine was excreted. Although the sputum culture showed normal flora, urine and blood culture detected Candida glabrata. $\beta$-D-glucan was $230 \mathrm{pg} / \mathrm{ml}$ and mannan antigen $2 \mathrm{u} / \mathrm{ml}$ (Table 2). Fundoscopic exam showed retinal exudates indicating mycotic endophthalmitis. We diagnosed candida glabrata sepsis from renal abscess. The patient was

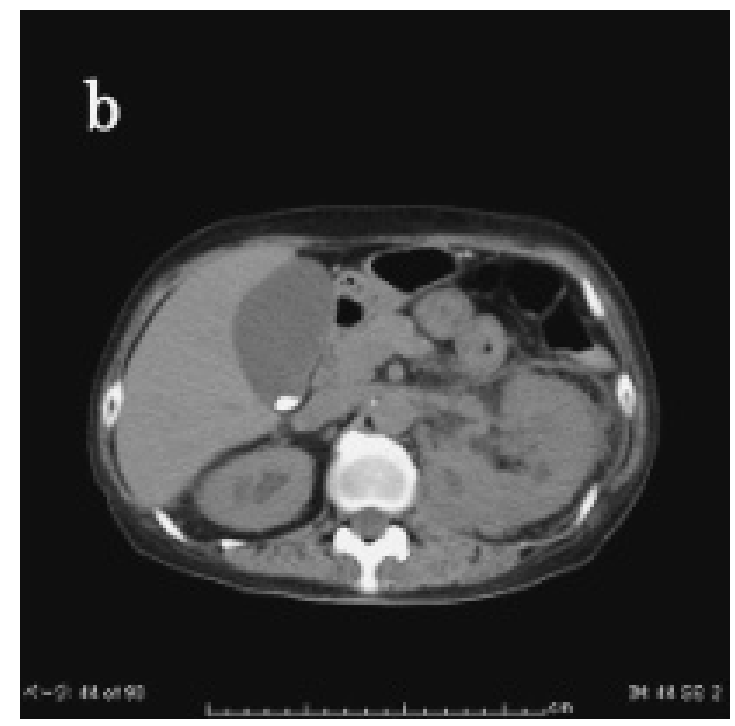

Fig. 2b Abdominal computed tomography shows renal pelvic dilatation and perirenal abscess in the left kidney.

Table 2 laboratory data 21 day after operation

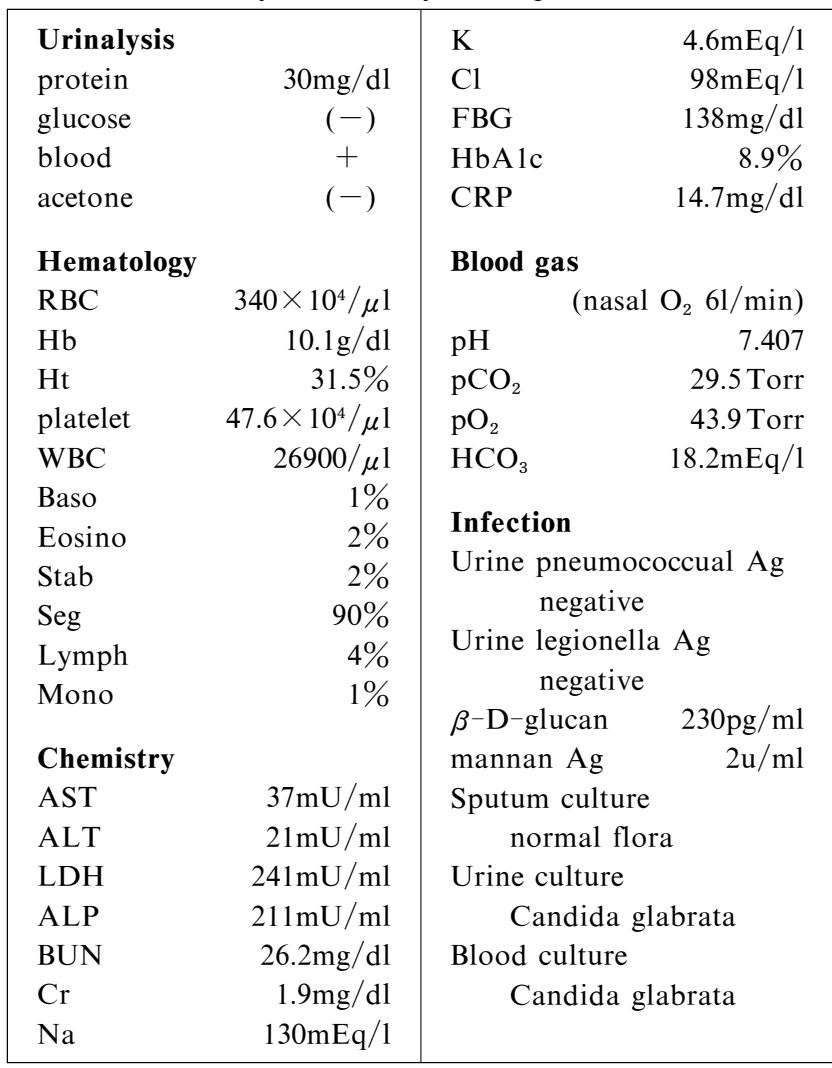

moved to the intensive care unit where in addition to $100 \mathrm{mg}$ of amikacin sulfate and $1 \mathrm{~g}$ of meropenem trihydrate for empiric therapy, a central vein pressure catheter was inserted and she was put on a respirator at low tidal volume ventilation and given $250 \mathrm{mg}$ of sivelestat sodium hydrate for acute respiratory failure. Administration of regular insulin aimed for a blood glucose range of 80 to $140 \mathrm{mg} / \mathrm{dl}$ for intravenous hyperalimentation. After using $200 \mathrm{mg}$ of micafungin daily, the patient's fever gradually decreased and her respira- 


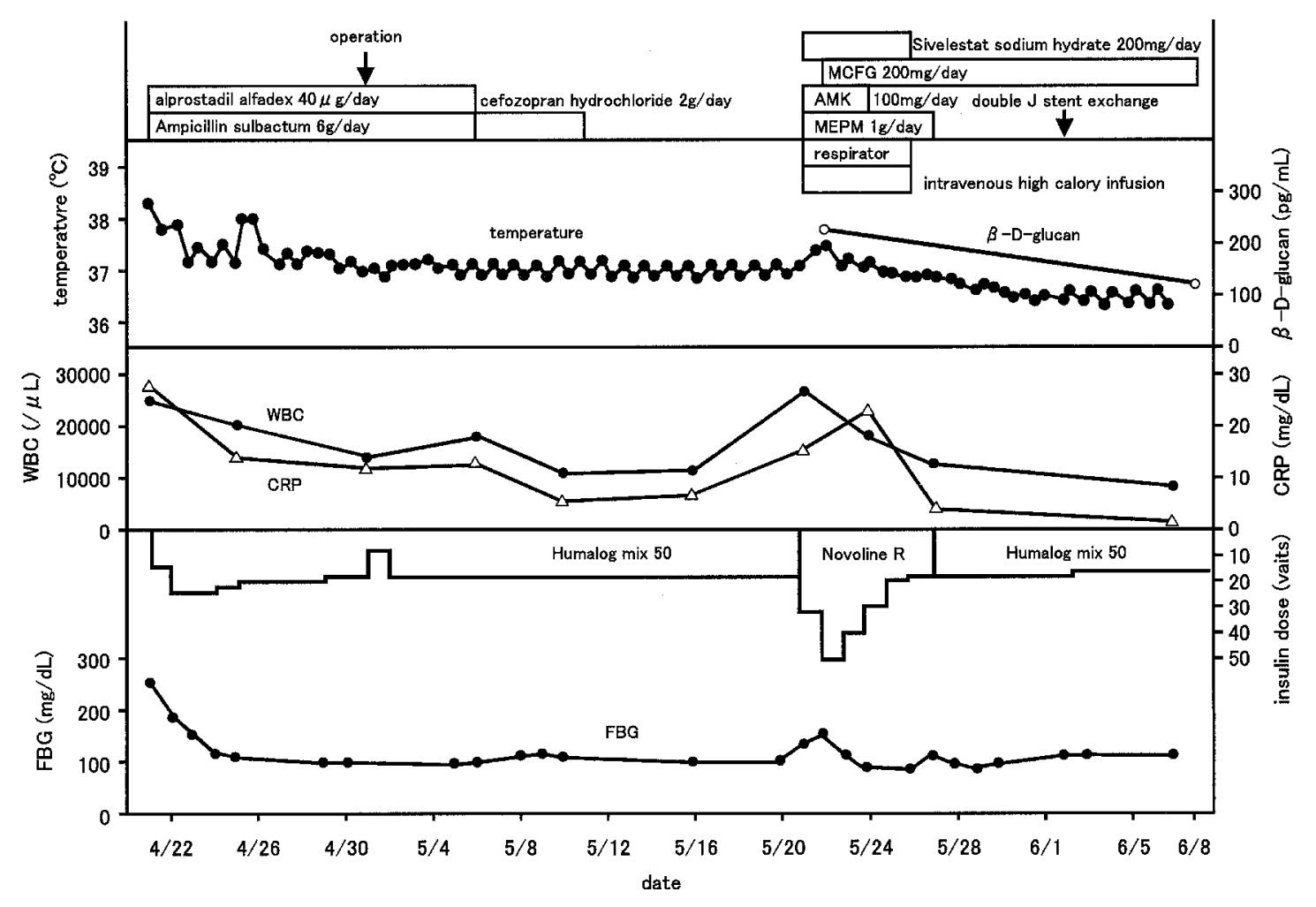

Fig. 3 Clinical course of the patient

tory condition improved. The patient did not need the respirator after 5 days and she became alert. We stopped intravenous hyperalimentation and started diet therapy and subcutaneous insulin infusion therapy (Humalog mix 50) again. The patient's fever normalized with decrease in the white cell count, CRP and $\beta$ D-glucan levels (Fig. 3). We then exchanged the double $\mathrm{J}$ stent and have exchanged it every 6 months. Fundoscopic exam showed background diabetic nephropathy alone 3 weeks after mycotic endophthalmitis occurrence.

\section{Discussion}

The patient had clinical manifestations featuring Candida glabrata sepsis after amputation of an infected diabetic foot and untreated diabetes mellitus with microangiopathy. The patient suffered from left renal pyelonephritis and a double $\mathbf{J}$ stent was inserted in the left ureter a year previously. She was then left untreated for diabetes mellitus and the stent had remained for a year. Staphylococcus aureus induced diabetic foot infections may occur in cases of hyperglycemia and diabetic neuropathy. ${ }^{3,4,5}$ Staphylococcus aureus and $\beta$ hemolytic streptococci are the most common pathogens in previously untreated diabetic foot infections. ${ }^{6}$ The Staphylococcus aureus was sensitive to Ampicillin-sulbactum in our case. However, the subfever continued after the amputation had been performed. Patients with severe diabetic foot lesions show a polymicrobial etiology. ${ }^{6,9}$ After we changed from ampicillin-sulbactum to cefozopran hypdrochloride for covering gram-negative pathogen, the CRP decreased but the subfever continued. At that time Candida glabrata surrounding the double $\mathbf{J}$ stent may have proliferated and caused left renal abscess. Urine and blood culture detected Candida glabrata. $\beta-\mathrm{D}^{-}$ glucan was elevated and mannan antigen was positive. Fundoscopic exam showed retinal exudates indicating mycotic endophthalmitis. Therefore, we diagnosed candida glabrata sepsis from renal abscess. Candidemia in critically ill patients is a significant source of mortality. ${ }^{10}$ Patients with prior surgery are at a higher risk fatality than others. ${ }^{11}$ This is compatible with our case. Candida glabrata is the second most common isolate of candidemia and the emergence of non-albicans species of Candida is the major cause of candidemia among diabetic patients. $^{8}$ The patient had suffered from hyperglycemia and diabetic neuropathy, and the double $\mathbf{J}$ stent had been inserted in the ureter for a year. Therefore, Candida glabrata may have remained alive surrounding the stent. An immunocompromised condition after leg amputation and broad-spectrum antibiotics such as cefozopran hypdrochloride may have caused Candida glabrata to proliferate and may have induced left renal abscess following candidemia induced mycotic endophthalmitis and pulmonary infiltration. Therefore, we administered micafungin and then the condition improved. Treat- 
ing Candida glabrata urinary tract infections can be difficult because the organism may be resistant to fluconazole. A newer antifungal agent, micafungin, provides an alternative and effective therapy against Candida glabrata. ${ }^{12}$ It is important for the prevention of severe infection to treat diabetes mellitus in addition to exchanging the stent in the ureter regularly.

\section{References}

1. Robbins SL, Tucker AW Jr. The cause of death in diabetes: a report of 307 autopsied cases. N Engl J Med $1944 ; 231: 865-868$

2. Shan BR, Hux JE. Quantifying the risk of infectious diseases for people with diabetes. Diabetes Care 2003; 26 : 510-513.

3. Delamaire $\mathrm{M}$, Maugendre $\mathrm{D}$, Moreno $\mathrm{M}$, et al. Impaired leukocyte function in diabetic patients. Diabetic Medicine $1997 ; 14: 29-34$

4. Hill HR, Augustine NH, Rallison ML, et al. Defective monocyte chemotactic response in diabetes mellitus. Clin Immunol 1983; 3: 70-77.

5. Marhoffer W, Stein M, Maeser E, et al. Impairment of polymorphonuclear leukocyte function and metabolic control of Diabetes. Diabetes Care 1992; 15: 256-260.

6. Bader MS. Diabetic foot infection. AM Fam Physician $2008 ; 78: 71-79$

7. Kauffman CA, Vazquez JA, Sobel JD, et al. Prospective multicenter surveillance study of funguria in hospitalized patients. The National Institute for Allergy and Infectious Disease (NIAID) Mycoses Study Group. Clin Infect Dis. $2000 ; 30: 14-18$

8. Bader MS, Lai SM, Kumar V, et al. Candidemia in patients with diabetes mellitus: epidemiology and predictors of mortality. Scand J Infect Dis. 2004 ; 36 : 860-864.

9. Anandi C, Alaguraja D, Natarajan V, et al. Bacteriology of diabetic foot lesions. Indian J Med Microbiol 2004; 22: $175-178$

10. Eubanks PJ, de Virgilio C, Klein S, et al. Candida sepsis in surgical patients. Am J Surg 1993; 166: 617-619.

11. Charles PE, Doise JM, Quenot JP, et al. Candidemia in critically ill patients : difference of outcome between medical and surgical patients. Intensive Care Med 2003; 29 : 2162-2169.

12. Lagrotteria D, Rotstein C, Lee CH. Treatment of candiduria with micafungin: A case series. Can J Infect Dis Med Microbiol 2007 ; 18 : 149-150. 